\title{
Features of Physical Development in Adolescents Aged 12-14 Years: Assessment and Analysis
} Nurgulim Akhmad*, Dinara Baigamyssova, Altyn Abilova, Ardana Balapanova, Umit Keldigulova, Gulzhan Alzhanbekova,
Meiramkul Okhanova

Asfendiyarov Kazakh National Medical University, Tole Bist. 94, 050000, Almaty, Kazakhstan

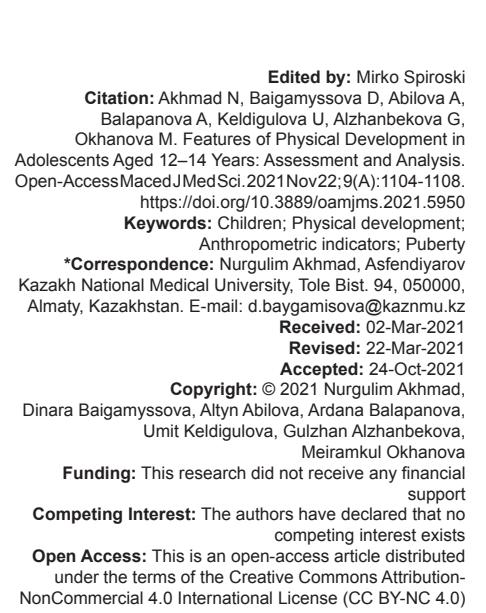

\section{Abstract}

BACKGROUND: The review examines the main stages of the formation of anthropometric monitoring of the physical development of children and adolescents in pediatric practice. Various factors that have a complex effect on the growth and physical development of the child's body are shown.

AIM: The aim of research is to identify features of physical development in adolescents aged 12-14 years and make assessment and analysis. The importance of conducting modern research to determine the anthropometric indicators of the norm for children and adolescents living in different regions is indicated. The research was conducted in educational institutions.

METHODS: A total of 756 boys and girls aged 13-14 were examined. The study of the main trends in the formation of physical and sexual development of children and adolescents over the past decade can serve as a basis for the development of measures to preserve reproductive health.

RESULTS: Assessment of the physical development of children showed that $72-73 \%$ of children aged $13-14$ years have a harmonious (normal) physical development. Among 14-year-olds, the deficit is relatively more common among girls, and the excess is the opposite among boys.

CONCLUSION: The progress of the external signs of puberty at the height of puberty was determined by the actual age (internal clock, i.e., the genetic program) and, in addition, and independently of this, the achieved body weight.

\section{Introduction}

Maintaining the health of the child population has become a strategic goal not only of national health care, and public policy in general, this is attributed to the progressive increase in the number of deviations in health status of children and the reduction of the share of healthy children. In all age and sex groups, the proportion of children suffering from chronic diseases has increased, and the level of morbidity in general and in certain classes of diseases has increased [1], [2].

Physical development is one of the criteria of human health and a demographic indicator of the health of the nation [3], [4]. Physical development is a natural process of changing the morphological and functional characteristics of the body, which is closely related to the age, gender, state of health, hereditary factors, and living conditions [5]. Back at the turn of the century, academician Veltischev (2000) outlined the children's health is the main focus in pediatrics. There is big increase in the number of children with chronic pathology, including the number of disabled children, as well as a decrease in the indicators of physical development and biological maturity among adolescents. To correct the methods of medical control in solving existing problems, it is necessary to develop complexes of biometric indicators (indicators of physical development, neuropsychiatric development, average values of peripheral blood, and humoral and cellular immunity) for each critical period (or stage) of children's development [4].

In recent years, a number of domestic and foreign publications have interpreted and analyzed the parameters of physical development in different ways. This is due to the introduction of various criteria of physical development into the practice of health care, including those from foreign sources. At the same time, the domestic experience in the analysis and evaluation of physical development is very extensive. A practical doctor and a research doctor will be useful in the formation of a comprehensive system for assessing physical development in children in our country.

The main stages of the formation of anthropometric monitoring of the physical development of children and adolescents consist in providing stepby-step effective care of children health. The first attempts to establish a link between a person's FR 
and their level of health were carried out in the Roman Empire, when the selection of soldiers was carried out on the basis of measuring their height. Hippocrates considered physical activity and fitness an integral part of physical and mental well-being. Aristotle first used the term "Anthropology" to refer to the science of man, which includes the assessment of physical development as a set of morphological and functional properties of an organism that characterize its growth and development. Height remained the leading criterion for assessing physical development until the first half of the $19^{\text {th }}$ century, when attempts were made to establish a relationship between height and body weight [6].

In the future, separate studies and publications of materials on the physical development of different age groups of the population, its dependence on hereditary, and environmental factors will be carried out. Significant for pediatrics was the works of its founders - N.P. Gundobin "Features of childhood" and V. I. Molchanov "Physiological data of childhood," which for many decades enjoyed well-deserved popularity in practical health care. Since 1917, in the USSR, the protection of motherhood and childhood has acquired a state character, a system of preschool institutions is being created that provide nutrition, education, and medical care for children on the basis of medical and hygienic standards [7].

Domestic and foreign scientists are developing various methods for assessing physical development, such as indices, which are described in more than 50 . The most common are

- Index A. Quetelet (mass growth) - the ratio of weight $(\mathrm{kg})$ to height $\left(\mathrm{m}^{2}\right)$, which is normally 185,249

- Index of L. I. Chulitskaya: From the sum of three circles - the circumferences of the shoulder, hip, and shin - subtract the length of the body. In infancy, the index of L. I. Chulitskaya is $20-25 \mathrm{~cm}$, in 2-3 years $-20 \mathrm{~cm}$, up to 7 years $-15 \mathrm{~cm}$, and in 7-8 years $-6 \mathrm{~cm}$

- Index of the F. F. Erisman (from the circumference of the chest, subtract half the length of the body); normally, the index is $13.5-10 \mathrm{~cm}$ in infants, 9-6 cm in 2-3 years, and $4-2 \mathrm{~cm}$ in $6-7$ years

- Proportionality indices - the ratio of head height to body length changes with age from $1 / 4$ to $1 / 8$, the ratio of the upper and lower segments decreases from 1.7 at birth to 0.93 in adults

- T. Brugsch index: Divide the chest circumference by the body length and multiply by 100 . The index is estimated from birth to 7 years; its value decreases from 65 to 53 .

Empirical formulas are the simplest method, a prerequisite for the use of which is the initial determination of growth and its compliance with age. In 1925, Martin proposed a parametric method for evaluating anthropometric data, which provides for the compilation of Sigma tables of the arithmetic mean values of a trait for a certain age and sex group and the value of the standard deviation. This method is most convenient for dynamic monitoring of the parameters of physical development of children and adolescents. Later, the non-parametric method of evaluating anthropometric data was used, which is the most objective and widely used all over the world. It is based on the comparison of the child's data with the average data of the corresponding age and sex group, considering the geographical area of residence [8], [9].

Since the 30 s of the $X X$ century, the attention of scientists has been attracted by the fact of acceleration of physical development; many theories of its occurrence have been formulated, such as radio wave, selection - urban, alimentary, and racial, but all scientists agreed that the main cause was the impact of the external environment on the body [10]. The phenomenon of acceleration has increased with each successive generation for 60 years, but in the last decade of the last century, doctors and anthropologists around the world described first its slowdown and then the reverse process (deceleration).

In children of the $1^{\text {st }}$ years of education, as a rule, functional disorders predominate in the state of health (Group II of health). In the process of learning and increasing academic load in children, the number of chronic diseases increases, chronic pathology is polysystemic in nature, in which diseases of the gastrointestinal tract are most often combined with a violation of the development of the musculoskeletal system, autonomic dysfunction syndrome, and thyroid pathology [5].

Ultimately, by the age of 15-18, the number of pathologies in a child almost doubles. In contrast to the last century, the structure of somatic diseases is dominated by diseases of the endocrine, urinary, nervous system, and mental disorders. The deterioration of the health status of children and adolescents has led to an increase in negative medical and social consequences [3], [5], [11], [12]. Thus, the increase in morbidity increases social maladaptation and disintegration, and leads to restrictions in the choice of profession. The number of teenagers-high school students who have restrictions in choosing a profession and professional training profile reaches 66\%. In addition, the unfitness for military duty more than half of young men of military age need a postponement from conscription for health reasons, the deterioration of the reproductive health of young men and girls significantly affects the potential of the country and its future [5], [13],

The factors of deterioration of health include lack of physical activity, improper organization of nutrition, lack of nutrition, stressful technologies, stressful nature of study, a significant amount of academic load, and violations of the daily routine. An important role is played by the environmental factor. High chemical technogenic 
load causes deviations in the physical development of children and adolescents [8].

Physical development is one of the most important generalizing indicators of a child's health. The identification of deviations in the terms of age-related development and disharmony of morphofunctional maturation allows not only to state certain changes in the state of health but also to determine the degree of risk of a particular disease.

The purpose of this study was to determine the age and sex characteristics of the physical development of children aged 13-14 years.

\section{Methods}

Children aged 13 and 14 were examined. The features of the physical development of adolescents of both sexes are revealed; the indicators of their puberty are studied and a comprehensive mathematical analysis of the relationship between the studied components of adolescent development is given (Table 1).

Table 1: Age and gender composition of the subjects

\begin{tabular}{llll}
\hline Age & Gender & & \\
\cline { 2 - 4 } & Boys & Girls & Total \\
\hline 13 years & 172 & 179 & 351 \\
14 years & 190 & 215 & 405 \\
Total & 362 & 394 & 756 \\
\hline
\end{tabular}

The study of physical development in groups of boys and girls aged 13-14 years was carried out by the method of clinical anthropometry with the determination of the height, body weight, level of physical development, and the degree of its harmony. The collection and processing of anthropometric data were carried out according to the standard methodology [8]. Body weight was measured on an electronic scale Tat1a (model VS-571, Japan) with an accuracy of $50 \mathrm{~g}$. Body length was measured using a rod anthropometer with an accuracy of $0.5 \mathrm{~cm}$.

The assessment of sexual development considered the presence and degree of development of secondary sexual characteristics in girls: Mammary glands (Ma), pubic $(P)$, axillary $(A h)$ hair, and the nature of menstrual function (Me); in boys - pubic $(P)$ and axillary (Ah) hair. The morphological maturity of the reproductive system was assessed by the level of puberty with integration into the sexual formula of the Maachrme [3].

\section{Results}

According to the results of our work, in particular, regression analysis, the increase in signs of puberty at the height of puberty was determined by the actual age (internal clock, i.e., the genetic program) and, in addition, and independently of this, the achieved body weight.

The physical development of modern schoolgirls has a number of deviations, deceleration processes persist, the average age of menarche remains stable, however, as numerous studies show, the formation of the menstrual cycle occurs with a lag.

According to the data from Table 2, 14 years old is on average $5 \mathrm{~cm}$ taller than 13 years old. Moreover, the increase in boys is more significant than in girls. Thus, boys grew by $7.9 \mathrm{~cm}$, and girls by $2.4 \mathrm{~cm}$, which is closely consistent with the mentioned normative data. If we compare it with a similar increase between 12 and 13 years (an increase of $6.8 \mathrm{~cm}$ in boys and $6.3 \mathrm{~cm}$ in girls), we note a clear slowdown in the increase in body height in girls, but its acceleration in boys. In other words, the age of 13-14 years is the period of attenuation of puberty growth in girls, but just the height of it in boys.

Table 2: The average value of the height and weight of the body in children aged 13 and 14 years (Mean \pm SD)

\begin{tabular}{llll}
\hline The group & $\begin{array}{l}\text { Number of } \\
\text { the subjects }\end{array}$ & $\begin{array}{l}\text { Body } \\
\text { length }(\mathrm{cm})\end{array}$ & $\begin{array}{l}\text { Body } \\
\text { weight }(\mathrm{kg})\end{array}$ \\
\hline 13 years & 317 & $159.2 \pm 0.4$ & $51.0 \pm 0.6$ \\
14 years & 340 & $164.2 \pm 0.4$ & $57.0 \pm 0.7$ \\
Boys & 311 & $162.8 \pm 0.6$ & $55.3 \pm 0.8$ \\
Girls & 346 & $160.9 \pm 0.4$ & $53.0 \pm 0.6$ \\
13 years - Boys & 153 & $158.7 \pm 0.7$ & $51.1 \pm 1.0$ \\
13 years - Boys & 164 & $159.5 \pm 0.5$ & $51.0 \pm 0.8$ \\
14 years - Girls & 159 & $166.6 \pm 0.7$ & $59.4 \pm 1.1$ \\
14 years - Girls & 181 & $162.0 \pm 0.5$ & $54.9 \pm 0.9$ \\
\hline
\end{tabular}

Boys of 14 years old were on average about $4.5 \mathrm{~cm}$ taller than girls, although at 13 , they were a centimeter shorter. This picture is also consistent with the regulations. As is known, in the age dynamics of the main anthropometric features, there is a double intersection of growth curves as a manifestation of sexual dimorphism, associated with different terms of entry into the processes of puberty of boys and girls. After the age of 10 , due to puberty, girls are taller, which continues until the age of 13 , when boys catch up with girls and even become taller.

The first intersection of the growth curves of the body length, when girls are ahead of boys in height, falls on 12 years, and at the age of 14 years, a pronounced excess of the body length in boys is revealed - the second intersection of the growth curves. This pattern is also noted by other authors. Thus, Bogomolova points out that a significant excess of the main anthropometric characteristics in boys persists from the age of 14 until the completion of growth processes [7].

Our 14 years old has an average body weight of $6 \mathrm{~kg}$ more than 13 years old. Boys are significantly heavier than girls at 14 years of age $(59.4 \pm 1.1 \mathrm{~kg}$ vs. $54.9 \pm 0.9 \mathrm{~kg}$ ). Almost $72-73 \%$ of children have a normal body weight ( $73 \%$ of boys and $72 \%$ of girls).

Among 14 years old, body weight deficiency is relatively less common compared to 13 years old, and 
Table 3: Distribution of children by body length options, depending on sex and age (in \%)

\begin{tabular}{|c|c|c|c|c|}
\hline \multirow[t]{2}{*}{ The length of the body } & \multicolumn{2}{|l|}{ Age $(\%)$} & \multicolumn{2}{|c|}{ Gender (\%) } \\
\hline & 13 years old & 14 years old & Boys & Girls \\
\hline Low & 2.2 & 2.8 & 1.5 & 3.3 \\
\hline Below average & 12.9 & 8.4 & 11.3 & 10.6 \\
\hline Average & 66.3 & 68.8 & 66.8 & 67.9 \\
\hline Above average & 16.4 & 18.4 & 18.5 & 16.2 \\
\hline High & 2.2 & 1.6 & 1.9 & 2.0 \\
\hline $\mathrm{N}$ & 317 & 250 & 265 & 302 \\
\hline
\end{tabular}

excess body weight, on the contrary, is more common. At the age of 14 , the body weight deficit is significantly more common among girls (14.5\%) than boys $(6.3 \%)$, and the excess is somewhat more common among boys (15.1\% vs. $10.1 \%$ in girls) (Table 3 ).

To identify the relationship between the rate of puberty of girls and three factors - age (in days), body length, and body weight - a regression analysis was conducted. Ordinal logistic regression was used. The variable "body weight" was previously prolongation to make its distribution more symmetric. The same dependence is observed in relation to axillary hair loss [4].

The researchers also found that in terms of the severity of sexual characteristics, modern schoolchildren are somewhat ahead of their peers of previous generations. This trend is well expressed in boys aged 11-13 and girls aged 9. The first signs of puberty in modern children appear at an earlier time: In boys from the age of 10 (in $2 \%$ - 1 degree of severity of hair in the armpits).

\section{Discussion}

A similar pattern was observed by other researchers. Thus, when distributing the categories of physical development by Maksimova and Lushkina, it was found that among boys, there are more children with increased and high body weight, and among girls - with reduced and low body weight $(1>2)$. These patterns are typical for both younger students (up to 10 years old) and older children (11-14 years old) [5]. A decrease in body weight in schoolgirls aged 14-17 years in comparison with girls of the 90s was noted by Arkhangelsk researchers [13].

The relationship between the variant of body length and body weight did not show a significant relationship. The above balance indicates the magnitude of the frequency overrepresentation or underrepresentation of this category compared to the expected one in the absence of communication. According to the remains, it is clear that children with a body length below the norm relatively rarely have a mass deficit.

The assessment of the sexual development of children, as mentioned above, was carried out according to the time of appearance and the degree of severity of secondary sexual characteristics. From the data presented in results section, it is clear that girls are ahead of boys in sexual development. Pubic hair outstrips axillary hair in both age groups and in both sex groups (Wilcoxon test, $p<0.01$ ). Menarche is present in $79 \%$ of girls by the age of 13 and almost $90 \%$ - by the age of 14 .

Thus, the conducted studies have shown that children of 14 years on average are $5 \mathrm{~cm}$ taller than 13 years old. Moreover, the increase in boys is more significant than in girls. Hence, boys grew by $7.9 \mathrm{~cm}$, and girls by $2.4 \mathrm{~cm}$, which is closely consistent with the data of other studies. As you know, between the ages of 7 and 9 , boys are about a centimeter taller than girls. After the age of 10 , due to puberty, girls are taller, which continues until the age of 13 and a half, when boys overtake and become taller than girls. The average body weight of 14 years old is $6 \mathrm{~kg}$ more than that of 13 years old. Boys are significantly heavier than girls at 14. An assessment of the physical development of adolescents showed that among 14 years old, body weight deficit is relatively more common among girls and excess on the contrary among boys. About 72-73\% of adolescents aged 13-14 years have a harmonious (normal) physical development [4], [9], [10].

According to the results of our studies, menarche occurred in $79 \%$ of girls by the age of 13 , in $90 \%$ - at the age of 14 . Undoubtedly, individual puberty, both in terms of the beginning and duration, in adolescents can vary significantly. However, the development of secondary sexual characteristics is confined to a certain passport age and occurs in a strict sequence of individual characteristics. Violation of this sequence may indicate deviations in the normal course of adolescent development and serves as the basis for the diagnosis of serious neuroendocrine disorders.

\section{Conclusions}

1. Assessment of the physical development of children showed that $72-73 \%$ of children aged 13-14 years have a harmonious (normal) physical development. Among 14 years old, the deficit is relatively more common among girls, and the excess is the opposite among boys.

2. A 14 years old is on average $5 \mathrm{~cm}$ taller than 13 years old. Moreover, the increase in boys is more significant than in girls. Hence, boys grew by $7.9 \mathrm{~cm}$ and girls by $2.4 \mathrm{~cm}$, which is closely consistent with the regulatory data. The age of 13-14 years is the period of attenuation of puberty growth in girls, but it is at its height in boys. Our 14 years old has an average body weight of $6 \mathrm{~kg}$ more than 13 years old. Boys are significantly heavier than girls at 14 . 
3. Girls are ahead of boys in sexual development. Pubic hair outstrips axillary hair in both age groups and in both sex groups (Wilcoxon test, $p<0.01)$. Menarche is present in $79 \%$ of girls by the age of 13 , in $90 \%$ - by the age of 14 .

4. The progress of the external signs of puberty at the height of puberty was determined by the actual age (internal clock, i.e., the genetic program) and, in addition, and independently of this, the achieved body weight.

\section{References}

1. Antonov OV. Scientific, Methodological and Organizational Approaches to The Prevention of Congenital Malformations in Children. Doctor of Medical Sciences, Omsk; 2007. p. 48.

2. Antsiferova ES. Complex Assessment of Physical Development of Candidates for Training and Pupils of Military Educational Institutions of Secondary General Education: Abstract of the Dissertation of the Candidate of Medical Sciences, St. Petersburg; 2007. p. 20.

3. BaranovAA, Shcheplyagina LA. Fundamental and applied problems of pediatrics at the present stage. Russ Pediatr J. 2005;3:4-8.

4. Veltischev YE. Problems of children's health protection in Russia. Perinatol Pediatr. 2000;1:5-9.
5. Deryabin VE, Fedotova TK, Gorbacheva AK. Influence of some biological factors on the somatic status of children aged 3-5 years. G N Speransky Pediatr. 2007;86(5):64-8.

6. Drozhzhina OA, Ippolitova LI, Yakuninskaya AM. Analysis of Physical Development and Structure of Morbidity in Children who have Suffered Severe Asphyxia in Childbirth [Electronic Resource]. Voronezh State Medical Academy named after N. N. Burdenko. Available from: http://www.airspb.ru/reger $21^{\wedge} \mathrm{sh} 1$ [Last accessed on 2021 Jul 15]

7. Kaznacheev VP, Peterson VD, Selyatitskaya VG. Physical development and health status of children in adolescence born to women who were ill during pregnancy. Bull SB RAMS. 2004;1(111):8-13.

8. Kozlov AI, Vershubskaya GG, Lisitsyn DV. Long-term changes in the anthropometric indicators of children in some ethnic groups of the Russian Federation. Speransky Pediatr. 2009;87(3):63-7.

9. Kotysheva EN, Jundzha NA, Bolotskaya MY. Analysis of anthropometric indicators of physical development of children 5-7 years old in the conditions of an industrial city. Speransky Pediatr. 2008;87(2):140-3.

10. Kranz VM. Physical development of children with renal pathology. Speransky Pediatr. 2007;86(1):73-9.

11. Lymar OA, Abushkevich VV. Morphofunctional features of physical development of children of primary school age of general education and special correctional schools. 2006;2(19):30.

12. Mamchik NP, Gabbasova NV, Kuprina NP. Probabilistic risk factors of the environment in the formation of morbidity with diseases. Speransky Pediatr. 2008;87(6):141-6.

13. Nagaeva EV. Growth as a criterion of child health. G N Speransky Pediatr. 2009;87(3):58-63. 